\title{
BUILDING BLOCKS OF INNOVATION WITHIN A STATE-OWNED ENTERPRISE (PART ONE)
}

\author{
BETSI VAN ZYL \\ GERT ROODT \\ JOHAN COETSEE \\ Department of Human Resource Management \\ University of Johannesburg
}

\begin{abstract}
This article (part one of a two-part study) presents a literature review aimed at establishing a theoretical framework on the innovation building blocks in a state-owned enterprise (SOE). Part two of the study will focus on SOE managers' espoused theory on the building blocks of innovation. The findings of the literature (theoretical) review, suggested that the current theoretical framework on innovation consisted of five important building blocks, namely contextual setting; strategic enablers; business enablers; foundational enablers; and human resources; each with its own categories and sub-categories. The study also identified barriers to innovation.
\end{abstract}

\section{OPSOMMING}

Hierdie artikel (deel een van ' $n$ tweedelige studie) bied ' $n$ literatuuroorsig aan wat die daarstelling van 'n teoretiese raamwerk van die innoveringsboublokke in ' $n$ staatsbeheerde onderneming (SBO) ten doel het. Deel twee van die studie sal op SBO bestuurders se voorgestane teorie oor innoveringsboublokke fokus. Die bevindinge van die literatuuroorsig (teoretiese oorsig) dui daarop dat die huidige teoretiese raamwerk van innovering uit vyf belangrike boublokke bestaan, naamlik 'n kontekstuele omgewing; strategiese bemagtigers; besigheidsbemagtigers; grondslagbemagtigers; en menslike hulpbronne; elkeen met sy eie kategorieë en subkategorieë. Die studie het ook innoveringshindernisse identifiseer.

Various authors stated through their discourses, their belief that innovation is the key to organisational survival and growth (Drucker, 1955; Handy, 1996; Hivner, Hopkins \& Hopkins, 2003; Kuczmarski, 1996; McGivern \& Tvorik, 1997; Mohamed, 2002; Tucker, 2003). However, few authors have attempted to build an integrated conceptual framework of the building blocks of innovation, e.g. authors such as Kuczmarski (1996) admitted that many executives today, similar to him twenty years ago, have not yet figured out how to create an environment that breeds innovation. In support of these notions, leaders and/or managers required a common point of reference in the shape of a conceptual multi-dimensional framework that dealt with the complex nature of innovation, which may be used and built upon in practice and research (Cooper, 1998). Subsequently, there is a need for the development of an integrated conceptual framework that pinpoints the building blocks of innovation to ensure that innovation, as a business practice, is applied and implemented.

\section{Objectives of the study}

The primary research objective of this two-part study is to compare a theoretical framework based on a current literature review of innovation building blocks with the SOE managers' espoused theory on the building blocks of innovation. The primary objective of the literature review in the current article (part one) will therefore be to establish a generic theoretical framework on the building blocks of innovation within organisations. The secondary objectives will be focused on: 1) approaches to innovation within organisations; 2 ) the barriers to innovation; and 3) the enablers of innovation. The research question and objectives were addressed by conducting a comprehensive, but not an all-inclusive literature review (refer to Figure 1).

\section{RESULTS}

The results of the literature review, as reflected by international literature, will be presented as follows:

- Approaches to innovation

- Inhibitors of innovation

- Enablers of innovation

Requests for copies should be addressed to: G Roodt, gertr@uj.ac.za

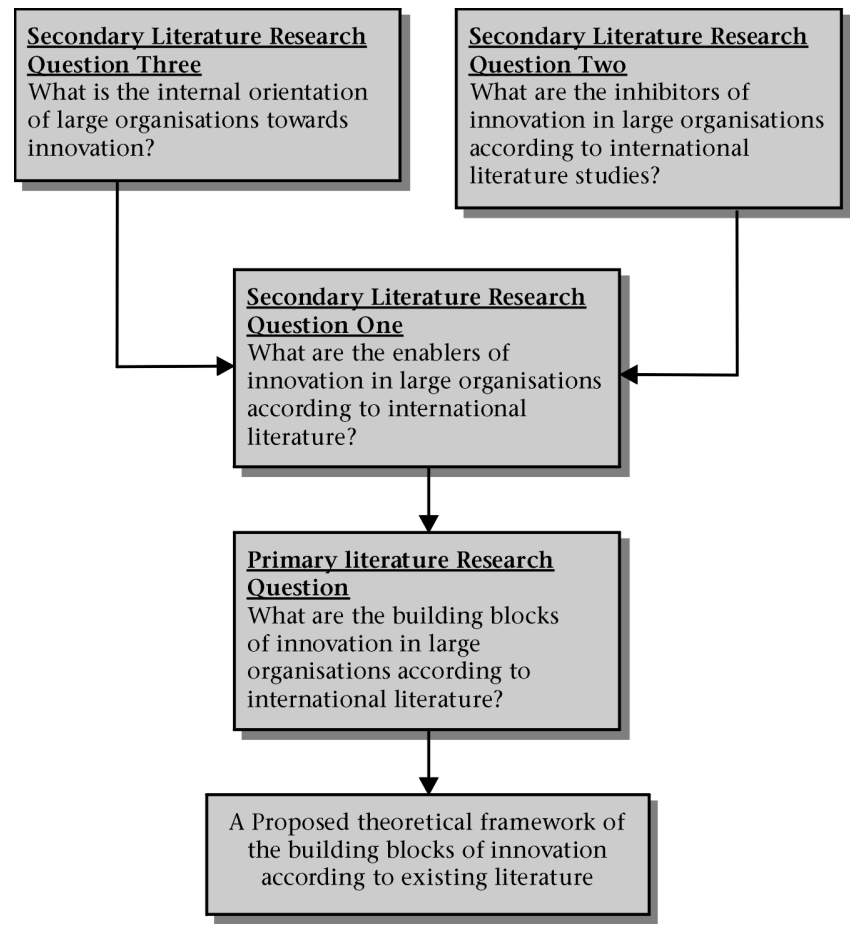

Figure 1: Diagrammatical presentation of the sequence of the literature research questions

\section{Approaches to innovation}

According to the literature review, approaches of large organisations towards innovation is influenced by important aspects, such as the macro economic setting of innovation focusing on the cycles of innovation inclusive of the well-known S-curve and adoption curve of innovation introduced by Rogers (1995), the classification and types of innovation and the drivers of innovation. All of these form the contextual setting of innovation within the organisation.

The economic setting of innovation: The interrelatedness between organisations and their market position is reflected in 
the approach that organisations take towards innovation. The economic patterns of innovation give to a large extent, an indication of the age of an industry, as innovation is linked to macro-economic patterns and fluctuation. Innovations tend to cluster in time and space, since there is often a strong interdependency among them as explained by Drejer (2002). Economists described the clustering or patterns as cycles or waves ("Kondratiev cycles"). Each wave represents a diffusion phase of innovations that could create entirely new industrial sectors. According to a comprehensive longitudinal study by Freeman and associates (1982) innovation patterns are based on short-wave patterns of about seven years in length. Each successive wave of innovation represents a linear extension of the previous pattern, as well as being a source of cumulating disruption. Each wave contains both incremental (linear) and radical (rupture) innovation described in a boom and bust manner (Economist, 1999; Freeman, 1982).

The Freeman-study (1982) extended the Kondratiev long-wave theory to recognise two other factors in the flux of innovations, namely institutional variables and technological variables. This study also noted that there tends to be a turn from product innovation to process innovation during the upswing of the economic cycle as larger volumes and lower costs are sought. At the other extreme are industries that are in a process of decline or stagnation with very little or no research and development activities and where much of the technical innovation that does take place comes from outside, from the suppliers of machinery, equipment and material.

Economically, the diffusion of innovation is very important. Freeman (1982) explained that the diffusion process of innovation is not simple carbon-copy replication, but frequently involves a string of further innovations. The diffusion theory of earlier days is linking up with the product-cycle and industrycycle theories of economists (Freeman, 1982). Schumpeter (Freeman, 1982) and his belief that the innovation diffusion process is inherently an uneven one has been confirmed by product life-cycle theory and international trade theory because first a few and then many organisations follow in the wake of successful pioneers. There is a hesitant start; fast growth and subsequent saturation followed by decline or stagnation, also referred to as the innovation adoption curve.

The Innovation Adoption Curve: The innovation adoption curve is described as the slowness with which an idea moves through the organisation and is picked up by the market. Rogers (1995) differentiated amongst adopters of innovations based on the time duration it takes them to adopt innovations. His various categories reflect the idea that certain individuals are more open to adaptation (change) than others. Although, the adoption process of innovation is linked with the diffusion process referred to earlier as described by Freeman (1982). Rogers (1995) differentiated the adoption process from the diffusion process.

The adoption process pertains to an individual, including rejection. Rejection is not to be confused from discontinuance. Discontinuance is a rejection that occurs after adoption of the innovation (Rogers, 1995). The diffusion process occurs within society, as a group process. The most striking feature of diffusion theory is that, for most members of a social system; the innovation-decision depends heavily on the innovationdecisions of the other members of the system. This movement is influenced by the market power that the organisation wields and is strongly linked to the well-known S-curve phenomenon. In other words the successful spread of an innovation follows an Sshaped diffusion curve (Brooking, 1997; Jones \& Kirby, 2002; Rogers, 1995). Jones and Kirby (2002) referred to it as the "legacy drag" (p.44).

The S-curve model offers an explanation of organisational growth, maturity, and progress over time. Products, services, processes, systems, structures, and business models - from the simplest to the most complex - go through three basic phases of growth and change before they must either leap to a new level of sophistication and complexity or die, hence the focus on breakthrough change and continuous change (Abraham \& Knight, 2001). Drejer (2002) explained the S-curve phenomenon from a technology approach to innovation. He divided the life cycle of a product/process into four elements; technological discontinuity, era of ferment, dominant design, and era of incremental improvement. A technological discontinuity represents a dramatic break with existing practice - and hence knowledge - in an industry. Disruptive changes, e.g. in the form of a technological discontinuity are the foundation of exnovation.

Exnovation or creative destruction refers to the removal of existing practices so that they can be replaced with new practices (Clark \& Staunton, 1990; Drejer, 2002). A distinction can be made between creative destruction and technology exploitation (Drejer, 2002). Rogers (1995) identified two types of discontinuance, namely disenchantment discontinuance and replacement discontinuance. Disenchantment discontinuance is a decision to reject an idea as a result of dissatisfaction with its performance. Replacement discontinuance is the decision to reject an idea in order to adopt a better idea. Both are intangibly part of innovation practices.

The drivers of innovation: The drivers of innovation provide the stimulus to move away from the status quo. Environmental factors, as drivers of innovation that affect the business environment, are deregulation, legislation, especially in regulated industries, the blurring of industries, globalisation of markets, continuous change and the growing importance of sustainability (Janszen, 2000; Jones \& Kirby, 2002). Competition, as a driver of innovation, is proposed as a driving force of innovation dynamics, such as the internationalisation of competition. A need exists for a dynamic view of organisational strategy in terms of both the external product-market perspective and internal competence perspective (Janszen, 2000 Jones \& Kirby, 2002; Pyka \& Küppers, 2002). Drejer (2002, p.4) referred to this as "hyper-competition", a concept coined by D'Aveni in 1994, which he (Drejer) quoted. Technology is proposed as one of the main drivers of innovation, such as the World Wide Web and e-business where new technology has been utilised as a business model (Janszen, 2000).

Classification of innovation: The need for organisations to understand the differences in the classification and nature of innovations spring from the fact that each innovation would require different resources, core competencies and management techniques in order for that innovation to add true value as described by Darroch and McNaughton (2002). Typically, innovation is classified according to the percentage change that the innovation engenders, e.g. the degree of strategic and structural change that the organisation must accommodate with regard to the innovation, namely radical or incremental (Clark \& Staunton, 1990; Cooper, 1998). Radical innovations refer to product and processes that result from advances in knowledge, whereas incremental innovation refers to the continual process of improvement of techniques (Mole \& Elliot, 1987). Literature shows that innovations are blended in the sense of having both radical and incremental elements. There are cycles of "altering" (radical) and "entrenching" (incremental) innovation (Clark \& Staunton, 1990, p.85) linked to the economic patterns of innovation.

Abernathy (in Urabe et al., 1988) made a distinction between two patterns of innovation, namely radical product innovation focusing on the maximisation of product performance; and incremental process innovation focusing on the improvement of the production process for the cost minimisation and increase of productivity and quality level, which form the link between radical and incremental innovation. He agreed that the mode of innovation shifts from radical to incremental as an industry 
matures. As a dominant product design is established and standardised, process innovation becomes the focus because cost and productivity become much more important as the focus of competitive strategy. Product innovations tend to decrease in relative importance in the mature stage of an organisation (Christensen \& Raynor, 2003; Grülke, 2001; Urabe et al., 1988).

The types of innovation: The types of innovation cited mostly in literature encompass technology, administrative and process innovation:

It is believed that technological innovation, because of its uncertainty, bears a large element of risk (Andriopoulos \& Lowe, 2000; Itami, 1988). Urabe et al. (1988) stated that technological innovation, usually linked to radical innovation, can not be realised without being accompanied by some kind of managerial innovation (also described as administrative innovation).

Administrative innovation is described as a software innovation such as a new approach, a new way, a new system, or a new technique towards strategy, marketing, personnel development, labour problems and management systems. Urabe et al. (1988) believed that incremental process innovation owes more to administrative innovation than to technological innovation. He cited the "KANBAN" system (JIT) production system as an example (Urabe et al., 1988, p. 6). The distinction between technological and administrative innovation is based upon the change that occurs in the operational core of the organisation. Technological innovation influences output processes and administrative innovations focus on the social structure of the organisation, such as policies, and allocation of resources as described by Cooper (1998).

Process innovation refers to the combination of a process view of the organisation with the adoption of innovation with regard to key processes (Davenport, 1993). This enables the organisation to achieve reductions in cost or time and improvements in quality, flexibility, and/or service levels. Process innovation includes new work strategies, e.g. low-cost producer strategies, process design activity and the implementation of change in all its complex technological, human and organisational dimensions. Finance is a powerful driver of process innovation as these initiatives could be linked to a need to improve financial performance. Process innovation can be distinguished from process improvement, which seeks a lower level of change, meaning slightly increased efficiency or effectiveness (Davenport, 1993; Zhuang, Williamson \& Carter, 1999). Process innovation is typically much more top down, requiring strong direction from senior management. Because large organisational structures do not reflect their cross-functional processes, only those in positions overlooking multiple functions may be able to see opportunities for innovation (Davenport, 1993). The orientation to innovation can be presented visually as in Figure 2.

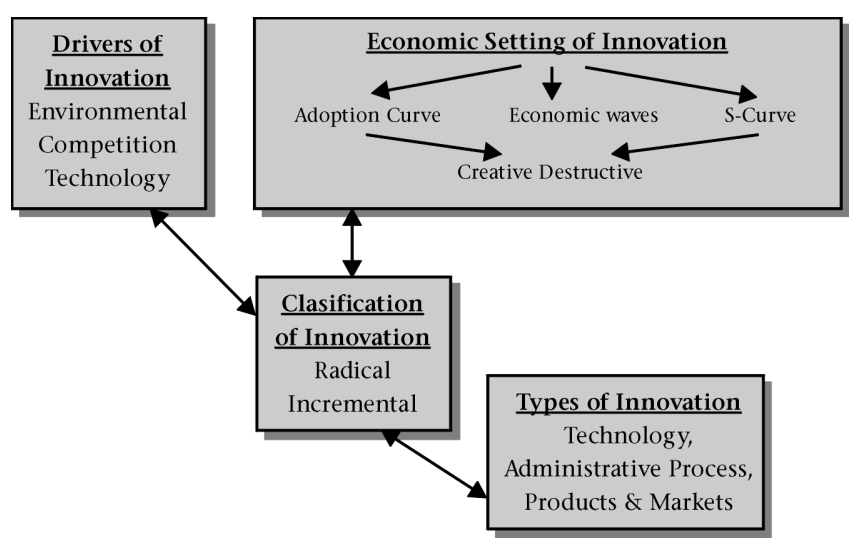

Figure 2: Contextual environment and approaches to innovation

\section{Inhibitors of innovation}

According to the literature there are generally accepted symptoms and causes of disabilities pertaining to innovation. These disabilities will be presented below:

Rigid Strategic Planning: The leadership, vision, strategic focus, valued competencies, structures, policies, and rewards that were critical in building an organisation's growth and competitive advantage during one period can become its Achilles heel as technological and market conditions change over time. In order to overcome these patterns of success followed by failure and of innovation followed by inertia, senior executives and managers must learn to lead in current markets while innovating for future markets. Leadership should therefore emphasize a current and a future perspective.

Culture: The flexible internal structures, competencies and cultures required to foster innovation for future success are often seen as a threat to the organisation's current rigid or routine priorities, practices and successes. Creative processes have an innate interactiveness; they require a freedom of action that cannot adhere to rigid, routinised or overly controlled environments (Quinn et al., 1997).

Leadership: Because innovation projects contain a risk element they are usually met with resistance and opposition and would therefore need the support from leaders/top management. Clear goals set by leaders would facilitate creativity and innovation. A Short-term view on profits increases intolerance for innovation and hampers any creative jobs (Andriopoulos, 2001; Kono, 1988; Tucker, 2002).

Intolerance: It is manifested in the organisation as high conformity, punishing norms, fear of getting it wrong, losing face, negative thinking and limiting innovation only to a specific department such as research and development (Andriopoulos, 2001; Gurteen, 1998; Kilroy, 1999; Tucker, 2002).

Strategic gridlock: This is a situation whereby an organisation goes overboard with alliances and networks, leaving no partners when the need arises. Although it might not seem like a hindrance to many of these partnerships, it also hinders innovation as the lack of time and overburdening of employees do. Emphasis on productivity and downsizing, which leads to more pressure on employees to work harder, is not conducive to creativity and innovation in an organisation (Arias, 1995; Tucker, 2002).

Tunnel vision: Gurteen (1998, p. 10) referred to "VOJ" (voice of judgement) in people's heads. This mechanism causes people to judge and criticise immediately. VOJ forms a creative strait-jacket (Buchen, 2003) where discussion, as opposed to dialogue, is regarded as detrimental to innovation. Discussions are rather focused on argument. It is about forcing agreement or compromise - in short, confrontation. It has nothing to do with creativity or the exploration of possibilities (Gurteen, 1998).

Structural Inhibitors: Monopolies with bureaucratic structures normally flourish in overly protected environments as they do not foster any visible creative and innovative capabilities that would facilitate competitive positioning (Borins, 2002). Borins indicated that organisational sociologists regard innovation in SOEs as an oxymoron.

\section{Enablers of innovation}

Innovation is an ancient art, maybe as old as 500000 years, but managing innovation is a relatively young management technique. Enablers of innovation within an organisation form the vehicle for that organisation to harness its innovativeness. Brodtrick (1999) described innovativeness as application of creativity through an established process that results in innovation. The literature study produced the following enablers as presented below: 
Strategy: Innovation at a strategic level encompasses strategy, vision, mission and funding. Strategy, as an enabler of innovation, encompasses two levels: The first level deals with the strategy and strategic intent of the organisation and the flexibility thereof. Strategic flexibility is the ability to adapt quickly and efficiently to changing environmental factors. This involves agility, versatility and resilience (Arias, 1995). The origin of creativity and innovation lies in a clear strategy, a shared vision and mission, which are focused on the future (Andriopoulos, 2001; Davenport, 1993; Johnson, 2000; Kono, 1988). Employees should understand the vision and mission (which support creativity and innovation) and the gap between the current situation and the proposed vision and mission to be able to act creatively and innovatively. Buchen (2003) stated that organisations that include innovation in their mission statements are holistically proactive and generate innovations that are future-oriented. In addition, organisational leaders should know how to effectively match the financial policy of the organisation with a particular phase of an innovation (Christensen \& Raynor, 2003; Kono, 1988). The second level deals with the strategy in terms of innovation per se and is described as an innovation strategy that promotes the development and promotion of new products and/or services. An innovation strategy guides and promotes the development and implementation of new products and services. It should be a directive and stabilising aid for innovative endeavours as described by Martins and Terblanche (2003).

Leadership: Strategy should be visionary and is cited as an important aspect of progressive leadership that should stimulate creativity and innovation (Christensen \& Raynor, 2003; Clark \& Staunton, 1990). Visioning ability refers to having a clear-cut vision for the organisation; a crucial ability when managing creative people (Andriopoulos, 2001; Uecke, 2002). This critical ability centres on strategic choices and is the start of a long-term probing into the future. Visioning is also an anticipation of strategic issues where discontinuities can emerge, which will impact on the structural architecture of the organisation (Clark \& Staunton, 1990). The most important requirement for effective visioning is a climate for intellectually open, creative thinking (Davenport, 1993). Leaders should stimulate creativity for two reasons, namely to prevent obsolescence and to increase productivity. The role of leaders is therefore important to the level at which innovative practices will occur in organisations. The visioning ability of leaders, their leadership style, development and habits, such as reading, e.g. business books, is especially important (Cooper, 1998). Tucker (2002) made the statement that executive leadership within an organisation should go on a "reading diet" (p. 108). According to Quinn, et al. (1997) observations have shown that, apart from reading, innovative people are well-informed and have what they called a "Culch Bag" approach (p. 142). This 'culch bag' consists of ideas, clippings, notes, observations and devices. When the need arises or an idea strikes, this culch bag is used to form new constructs that change past stasis. This is important in view of the argument put forward by Cottam, Ensor and Band (2001) where they indicated that senior management did not have the right skills to encourage or foster innovation. The appropriate leadership model for creativity and innovation is democratic, accessible and participatory (Andriopoulos, 2001; Uecke, 2002). Leaders cannot force creative thought, but they can recognise and value it when it emerges, by implementing the idea (Slywotzky \& Wise, 2003). Consequently, leaders can promote creativity and innovation by employing business processes that create an internal work environment that stimulates the workforce to be more creative and innovative (Ahmed, 1998, Martins \& Terblanche, 2003)

Culture: Organisational culture forms the baseline that facilitates a shared system of meanings and enhances corporate communication and mutual understanding (Martins \& Terblanche, 2003; Veldsman, 2002). Some literature dealing with culture from an innovation angle has shown that there is little agreement on the type of organisational culture needed to improve creativity and innovation. There also seems to be a paradox in the sense that organisational culture can stimulate or hinder creativity and innovation (Martins \& Terblanche, 2003). However, there is substantial literature indicating that organisational culture seems to be a critical contributing factor regarding the degree to which creativity and innovation are stimulated (Ahmed, 1998; Andriopoulos, 2001; Martins \& Terblance, 2003; Thomson, 1998).

Tucker (2002) emphasised an innovation-adept culture is the building block that forms the basis of future innovation practices. Andriopoulos (2001) indicated that organisations need to develop innovative and supportive cultures, which he translated by using words, such as divergent, learning, empowering and caring. Clark and Staunton (1990) referred to a "thinking corporate culture". They indicated that innovativeness would be enhanced by what they call "frontend intellectual loading" (p. 120). This means that corporate culture provides the necessary language (cognitive and affective) infrastructure for the innovation process. The assumptions of the work force in the organisation on how to act and behave within the cultural environment will have an impact on the degree of creativity and innovation in the organisation through socialisation processes. Individuals will, in accordance with shared norms, make assumptions about whether creative and innovative behaviour forms part of the way in which the organisation operates (Martins \& Terblanche, 2003). Ahmed (1998) cited studies by other researchers that indicated a definite link between culture and innovativeness. They defined four generic culture types, namely market culture, adhocracy culture, clan culture and hierarchical culture. These studies have shown that certain culture types are more able to enhance innovativeness such as the market and adhocracy types that are less rigid, but more organic, fluid, flexible and responsive.

Janszen (2000) and Grülke (2001) both believed that an entrepreneurial culture is needed for innovation to take place within an organisation. Grülke (2001) also indicated that it is extremely difficult to recreate the kind of entrepreneurial culture experienced in the first half of a business cycle when the efficiency culture of the second half of the business cycle is the norm. This is why mature organisations experience difficulties with the entrepreneurial approach. Pech (2001) believed that a culture of individualism and leadership results in new ways of doing things, such as new products and services. He refers to an open culture espousing loyalty, trust, and helpfulness. It is an atmosphere of co-opetition, (a seemingly paradoxical combination of co-operation and competition). Several authors (Arad, Hanson \& Schneider, 1997; Martins \& Terblance, 2003) indicated that an organisational culture that supports a continuous learning orientation should encourage creativity and innovation. A learning culture can be created and maintained by focusing on being inquisitive, by encouraging personnel to talk to one another (e.g. to clients within and outside the organisation to learn from them), by keeping knowledge and skills up to date and by learning creative thinking skills.

Amabile (1988) and Martins and Terblanche (2003) explained the relationship between organisational culture and creativity and innovation in terms of the external environment where economy and competitiveness encourage continual changes in products, technology and customer preferences. They referred to the innovation strategy that reflects the reaction of the organisation to critical incidents inside and outside the organisation, as well as managers' values and beliefs (e.g. free exchange of information, open questioning, support for change, diversity of beliefs). They also referred to the flexible structures of organisations that are characterised by decentralisation, shared decision-making, low to moderate use of formal rules and 
regulations, broadly defined job responsibilities and a flexible authority structure with fewer levels in the hierarchy. They also discussed technology, which includes knowledge of individuals and availability of facilities, such as access to the Internet to support the creative and innovative process.

Climate: Culture is a reflection of climate, but operates at a deeper level (Ahmed, 1998; Buckler, 1996; Cooper, 1998). Juniper (1996) referred to climate as the mental health of the organisation. Andriopoulos (2001) referred to climate as the mood or atmosphere existing in an organisation. McAdam and McClelland (2002) used Amabile's theory on individual creativity to indicate that any person can be creative. It is the work environment that influences the level and frequency of this creativity. A perpetually challenging climate, supported by appropriate values, should be encouraged where people can discuss and share their ideas freely and where assumptions can be questioned in a positive manner (Amabile, 1998; Andriopoulos \& Lowe, 2000; Andriopoulos 2001; Kono, 1988; McAdam \& McClelland, 2002). Ahmed (1998) quoted Scheider who defined four dimensions of climate, namely the nature of interpersonal relationships; the nature of hierarchy; the nature of work and the focus of support and rewards all of which impact on innovation and the adoption thereof in a systemic manner.

Values: Uecke (2002) indicated that core values are sub-factors that support creativity. The following values were cited by authors as important for innovation, namely trust is needed to form a solid basis for teamwork (Andriopoulos, 2001; Uecke, 2002) with commitment to encourage innovation and acceptance of risks that go hand in hand with innovation (Gratton, 2000); support for change and a positive attitude towards change (Arad et al., 1997; Johnson, 1996; Martins \& Terblanche, 2003); tolerance of conflict, e.g. between different ideas and handling that conflict constructively (Mumford, Whetzel \& Reiter-Palman, 1997; Martins \& Terblanche, 2003). The values cited above, hint towards the required business processes that would include values in the daily operations of the organisation and would also manage the fuzzy front end of innovation as described by Kim and Wilemon (2002). These processes will be presented in more detail.

Management practices: Organisations that wish to be innovative need forward-looking management practices, such as strategic judgment and evaluation (Buchen, 2003; Wu, Chiang \& Jiang, 2002). Cooper (1998) believed that innovation is not a one-time event. Peters and Waterman (1982) published common denominators that fostered creativity and innovation. Their analysis showed that the successful companies have built-in management mechanisms that stimulate new ideas and the pursuit of those ideas by intrapreneurs (in-house entrepreneurs). The innovation paradox is that the unpredictability with regard to innovation needs a stable disciplined management system and process to nurture the growth and development of unplanned opportunities. On the other hand, management practices should also encourage creative tension. Creative tension refers to the notion of deliberately stimulating competition. It is believed that without challenge there are not enough stimuli to elicit creative responses (Peters \& Waterman, 1982; Senge, 1990). The management system should be a combination of leadership skills and management processes and should include the following areas:

Exploration, which is a search for undisclosed needs; potential new markets; customer segments; business model adaptations; experimentation, which may include pilot projects; attempts to test potential opportunities for viability; learn what would be needed to make it successful; development where resources are committed to develop or refine the new products and/or services and integration where the new product is fully commercialised (Buchen, 2003; Cooper, 1998; Wu, Chiang \& Jiang, 2002).
Business processes and systems: Cooper (1998) indicated that organisational processes and procedures are important to the adoption of innovation and is supported by Andriopoulos (2001) who referred to systems within an organisation as a determinant of organisational creativity. Amabile and Gryskiewicz (1997), quoted by Uecke (2002), mentioned amongst others factors such as ideas management system, reward system, and performance management. These and other identified practices/processes and systems are:

- Recruitment and Staff Process: Knowledge of Kirton's adaption-innovation (KAI) theory would facilitate the creation of the right balance between adaptor and innovator type of persons, who are both important to different stages within the innovation process (Andriopoulos, 2001; McAdam \& McClelland, 2002, Johnson, 2001)

- Diversity Management Process: Diversity management is essential to optimise the creativity of a heterogeneous group (McAdam \& McClelland, 2002; Tucker, 2002). Justesen (2001) described vicious circles of diversity (miscommunication, intergroup anxiety and goal incongruence) that impede innovation and virtuous circles of diversity (absorptive capacity, requisite variety, network variety, creative destruction, and enhanced problem-solving skills) that advance innovation.

- Reward System: Andriopoulos (2001) discussed generous recognition of creative work and active encouragement, which translates into a reward and recognition system. $\mathrm{He}$ and other authors linked the rewards system to motivation. Intrinsic motivation is a key driver of creativity. Intrinsically motivated employees should be identified and assigned jobs involving creativity to enhance the emergence of new ideas (Ahmed, 1998; Kono, 1988; McAdam \& McCelland, 2002; Uecke, 2002).

- Performance Management Process: Successful innovative organisations evaluate on four levels according to Quinn et al. (1997). These four levels are individual performance (peers), customer performance (customers), collaborative performance (group members/customers) and organisation performance (value-add measures). Kaplan and Norton (2004) indicated that innovative processes have a longer-term focus and measurement tools should reflect that.

- Knowledge Management Process: "Knowledge Management is an emerging set of organisational design and operational principles, processes, organisational structures, applications and technologies that help knowledge workers dramatically leverage their creativity and ability to deliver business value" (Gurteen, 1998, p.6). Knowledge is regarded as a source of competitive advantage and therefore a corporate asset (Darroch \& McNaughton, 2002; Ferrari \& Toledo, 2004). The American Productivity and Quality Center (APQC) undertook a study called Using Knowledge Management to Drive Innovation. The results of the study showed that effective knowledge management does create successful innovation. The study also highlighted functions that are supportive and enabling to both knowledge management and innovation, such as an effective information technology system, communities of practice (cross-disciplinary knowledge), culture change, human resource practices, infrastructure and resources (Strategic Decision, 2004). However, whilst agreeing with the results of studies as mentioned above, Darroch and McNaughton (2002) indicated that the relationship between knowledge management and innovation is not well understood. Taking an idea (creativity) and turning it into action (innovation) requires the application of existing knowledge and the development of appropriate new knowledge (Gurteen, 1998). From that viewpoint knowledge management is seen as the basis for intellectual capital through innovation capital.

- Change Management Process: Innovation is closely related to organisational change. Ahmed (1998) argued that innovation 
is the engine of change, and that innovative changes are very sensitive to context. According to Quinn et al. (1997) researchers have indicated supporting, innovative issues that are crucial to successful change processes. These issues are building adaptive capabilities, which are needed for incremental and transformational change and to establish change competencies. Change should be seen as the realignment across the vertical, horizontal and temporal axes of the organisation so that a capability for renewal and adaptation can be developed (Gratton, 2000). A holistic approach should thus be taken, as innovation is systemic by nature. Change brings risk and uncertainty, but it also brings opportunities. The organisation should therefore develop the required profile to seize these opportunities and deal with the uncertainties (Gratton; 2000; Quinn et al. 1997).

- Risk Management Process: Taking risks and experimenting are behaviours that are associated with creativity and innovation (Brodtrick, 1999). A culture in which too many management controls are applied will inhibit risk taking and consequently creativity and innovation (Judge et al., 1997). Literature emphasised that the corporate climate must be tolerant towards errors, accepted as part of taking the initiative and should be viewed as learning experiences (Andriopoulos, 2001; Martins \& Terblanche, 2003; Tucker, 2002). However, it is important that a balance should be reached in the degree to which risk-taking is allowed. These risks are based on sensing and critical thinking skills and should be regarded as calculated risks (Johnson, 2001).

- Scanning Ability: Kono (1988) stated that an extensive process of information collection is needed for innovation. He further referred to formal and informal sources of information such as customer needs; new products by competitors; trends in new technology; trends in the general environment; and the strengths of the company. This scanning process for opportunities was labeled as "mining the future" by Tucker (2002, p. 107). He stressed the importance for organisations to stay abreast of trends and new ideas. In a similar vein, the "white space" technique (Quinn et al., p. 149) can be used for exploring totally new or unexploited opportunities.

- Quality Management Process: Authors on quality and innovation agreed that quality is doing things better; innovation is doing things differently and that both are needed. When a company is an industry leader, quality processes can produce incremental improvements that will help maintain its leadership position - for a time. However, to maintain competitive advantage over the long term, companies need to innovate to push ahead (Samaha, 1997). It is believed that a quality management process and/or system in an organisation create an environment, which is conducive to successful innovating activity, such as ideas generation (Silverman, 1999).

- Ideas Management Process: McAdam and McClelland, (2002) referred to a study done by Sowrey in 1987 in which he found that companies that utilised idea generation systems actually produced a larger number of new products as opposed to those companies who did not. The management of an Idea system can help the organisation to incorporate innovation as a business discipline (Andriopoulos, 2001; Ahmed, 1998; Kono, 1988; Tucker, 2002; Zhuang et al., 1999). Therefore, large organisations can be just as innovative as small companies through an ideas management system (McAdam \& McClelland, 2002). Tucker (2002) referred to ideation as a systematic process with the specific goal to generate ideas by using specific techniques in order to develop new products, services or systems. He mentioned the use of "ideation rooms" (p. 60) to foster creativity.

- Communication Management: The role of communication is stressed by Andriopoulos (2001); Cooper (1998) as well as Martins and Terblanche (2003). An organisational culture that supports open and transparent communication, based on trust, will have a positive influence on promoting creativity and innovation. Communication should be based on dialogue that is nonjudgemental, exploring, inquiring and creative as opposed to discussion, which is judgmental, confrontational, defensive and destructive (Gurteen, 1998).

- Relationship Management Process: Leaders, especially team leaders, should promote creativity in teamwork, but they can only do so if they are aware of the complexities of teamwork relationships and also if they have knowledge on how to nurture and utilise these relationships in a positive way (Cooper, 1998). This can only be achieved by real insight into relationships and by understanding the underlying contractual relationship, also including financial and psychological issues (McAdam \& McClelland, 2002; Gratton, 2000). For example, an organisation-customer relationship can be a critical gateway to address unmet customers needs (Slywotzky \& Wise, 2003).

Customers: Creativity as a resource should be focused on meeting the needs of customers. Profitable new products (innovation) can be generated by first identifying the needs of customers and second by generating ideas and solutions to address those needs. This customer-pull (or market-pull) approach to knowledge creation and idea generation with lead users is used for instance by $3 \mathrm{M}$ and Hewlett Packard (McAdam \& McClelland, 2002). However, Darroch and McNaughton (2002) referred to statements that incremental innovation is more aligned to customers needs. Radical (or technologypush) innovation by definition ignores customers' needs, because it is either new to the world or new to the organisation. This is often presented as a reason why so many radical technological innovations fail. Therefore, a balance should be maintained between market-pull and technologypush strategies with regard to innovation.

Human resources: Creativity, resulting in innovation, is possible for most individuals at work (Gurteen, 1998; Henry, 2001). Kono (1988) stated that a creative organisation, and therefore an innovative organisation, would need people with different and complementary capabilities. Drejer and Riis (2001) labelled them as focus competencies - those required competencies for tomorrow's needs. These competencies are:

- Emotional Intelligence: To excel in today's competitive business environment, organisations need members who can move beyond cognitive intelligence (IQ). Emotional intelligence is described as the capacity to reason with emotion in four areas: to perceive emotion, to integrate emotion in thought, to understand emotion and to manage emotion. Consequent studies on emotional intelligence have found that people with high emotion regulation abilities seem to form more satisfactory relationships with others on various levels. Emotionally intelligent persons accept the inherent ambiguities and tensions that are so prevalent when dealing with innovation. Workers are willing to offer ideas and work cohesively without fear of criticism or ridicule (Gratton, 2000; Goleman, 1995; Sy and Côté, 2004).

- Creativity: Creativity, starting with imagination, feeds upon itself, producing more creative ideas. Juniper (1996) believed that creativity must be demystified. The concept of creativity must be understood in the sense that effective working is creative working. It must also be understood that creativity is about divergent thinking. Innovation is about convergent thinking. Therefore, creativity is not enough. Innovation is needed to activate creativity (Gurteen, 1998). McAdam \& McClelland, (2002), using Amabile's componential theory of creativity, indicated three components to individual creativity, namely, expertise (linking to relevant skills and knowledge); creative-thinking skills (ability to consider different perspectives independently) and task motivation (intrinsic motivation is more conducive to the processing of 
divergent information). As creativity is affected by skills such as expertise, technical skills, talent and mental flexibility it would be beneficial to the organisation if those skills are clearly understood and conceptualised (Ahmed, 1998; Henry, 2001; Zhuang et al., 1999).

- Core Skills: Andriopoulos (2001) referred to skill as a determinant of organisational creativity. Cooper (1998) stressed that different skills are needed in the different stages of the innovation process. Organisations need people with "T-shaped" skills, which is explained as deep vertical knowledge and strong lateral associative skills (Quinn et al., 1997,p. 29).

- Creative and Hybrid Thinking Skills: Organisations tend to encourage analytical thinking rather than creative thinking. This limits creativity and innovation, as idea generation is limited. Hybrid Thinking is a higher-order thinking process that incorporates both creative and analytical modes of thinking, namely intuitive thinking where information stimulates the mind to produce an idea, formative thinking where insight is used to mould the idea into a concept (or a value-adding proposition) and logical thinking where the idea is evaluated sensibly, e.g. customer value analysis (Kilroy, 1999; McAdam \& McClelland, 2002).

- Systems Thinking Skills: Systems thinking (systemic capabilities) would ensure vertical and horizontal alignment of the innovative activities with the strategies of the organisation. The organisation and its innovations must be seen as a whole and not just as different functions each with its own separate new products and services (Ahmed, 1998; Gratton, 2000).

Organisational learning: In the ever-changing business environment, an organisation's capacity to learn must exceed the rate of change it has to cope with. Organisational learning is a dynamic process based on the transfer of learning from individual to organisation. Therefore, learning takes place on two levels, namely on individual level and on organisational level, that involves learning new things continuously, as well as unlearning old things. Learning from failures is interpreted as reflective learning (Andriopoulos, 2001; Buckler, 1996; Johnson, 2001; McAdam \& McClelland, 2002; Tucker, 2002).

Entrepreneurship: It is generally understood that corporate entrepreneurship consists of intrapreneurship (new ventures within and surrounding a current organisation) and dispersed entrepreneurship (structures/cultures to foster entrepreneurs/innovation) (Drucker, 1985; Sundbo, 1998; Quinn et al., 1997). Dispersed entrepreneurship is also labelled as "questocracy" by Johnson (2001, p.138). Intrapreneurship refers not only to the creation of new business ventures, but also to other innovative activities and orientations, such as development of new products, services, technologies, administrative techniques, strategies and competitive postures. Its characteristic dimensions, are new business venturing, product/service innovation, process innovation, self-renewal, risk-taking, proactiveness, and competitive aggressiveness. New business (new company) creation is the most obvious manifestation of entrepreneurship in the economy. A distinction could be made between conservative (risk averse, noninnovative, and reactive) organisations and entrepreneurial (risk-taking, innovative, and proactive) organisations. Entrepreneurship in organisations is therefore a matter of degree (Bostjan \& Hisrich, 2003; Drucker, 1994).

Structure: McAdam and McClelland (2002) cited research studies that indicate structural flexibility is one of six top drivers for innovation within an organisation.

These authors argue that a-typical structures are necessary for innovation, as innovation is a non-linear process which therefore needs a non-linear structure. Yet it seems that few organisations have actually restructured around the imperatives of implementing and managing innovation (Andriopoulos, 2001; Cooper, 1998; Martins \& Terblanche, 2003; Urabe et al., 1988; Quinn et al., 1997). It is said that innovation is enhanced by organic rather than mechanistic structures (Hellström et al., 2002). It is suggested that a fluid, organic type of organisation fits the early development stage where radical product innovation is prevalent, whereas a highly structured, mechanistic type of organisation with attendant job specification procedure fits the mature development stage where incremental process innovation becomes the prevalent mode of innovation. In other words, a mechanistic structure is seen to be appropriate if the environment is stable and predictable with simple markets and well-defined parameters (Sy \& Côté, 2004). An organic structure is appropriate to facilitate innovation in an unpredictable environment (Ahmed, 1998; Quinn et al., 1997).

Organisations that are innovative tend to favour "Adhocrasies" (Quinn et al., 1997, p. 14). Adhocrasies, as they described it, referred to what is known today as multi-disciplinary teams that form for a specific purpose. Innovative structures are the opposite of power-centered, discipline-orientated or functional structures as often found in large, mature organisations. Bureaucratic layers discourage cross-functional interaction as reporting lines are clouded and the power base is eroded. The concept of innovation is better represented by organic, circular constructs. This indicates fluid boundaries. The effectiveness of these structures is based on stimulating an aligned purpose, open information-sharing and a rich and profuse network(s) of relationships (Quinn et al., 1997). Responses to the dilemma of a fitting organisational structure to support innovative practices are the matrix organisational structure (Sy \& Côté, 2004); Multi-disciplinary teams (Cooper, 1998; McAdam \& McClelland, 2002; Tucker, 2002; Uecke, 2002); networks (Arias, 1995; Slywotzky \& Wise, 2003; Tucker, 2002; Uecke, 2002); collaboration as a purposive relationship. Margaret Wheatley in Quinn et al. (1997) noted: "innovation is fostered by information gathered from new connections; from journeys into other disciplines; from active collegial networks and fluid open boundaries. Innovation arises from ongoing circles of exchange, where information is not just accumulated and stored, but created" (p. 136).

Technology: Technology, e.g. information technology serves as an enabler for innovation across the value chain (production and administration) to deal with the innovation from input to output (Andriopoulos, 2001; Drejer, 2002; Martins \& Terblanche, 2003). Lack of resources can constrain creativity as all energy is aimed at finding resources and not at developing the new idea into a viable product. In addition, the capacity to develop and manage software is indicated as a core skill for generating innovation (Quinn et al., 1997).

\section{DISCUSSION}

It would seem, from the literature presented, that individual activities/processes across disciplines within an organisation could collectively impact on innovation and its practices. When these activities/processes are practiced in a positive way it could be regarded as enablers of innovation within an organisation. These enablers include strategic, leadership, human, business process and culture practices, each with its own sub-elements, can be regarded as building blocks of innovation. These enablers are needed at every level and in every functional discipline within an organisation, both on an individual and an organisational level (Cooper, 1998; Gurteen, 1998). Tucker (2002) regarded the knowledge about innovation inhibitors as crucial if an organisation wishes to incorporate innovation into their daily practices. The mentioned inhibitors are therefore included in the theoretical framework presented at the end of this article. 
The building blocks of innovation, presented as a framework, reflect the complexity and systemic nature of innovation and how far, deep and wide organisations must embrace elements that would ensure innovation and its practices within an organisation. It shows clearly that innovation deals with various elements and activities, which need input from different roleplayers across and external to the organisation in order to create innovations. The framework will be discussed below according to the broad categories.

\section{Contextual setting of innovation}

This forms the broad backdrop to and in which all organisations must respond in order to function as an organisation. The contextual setting of innovation consists of the economic setting of innovation, the drivers of innovation, the classification of innovation and the types of innovation. The economic setting of innovation included the influence that economic patterns have on innovation, described as "Kondratiev Cycles" (Freeman, 1982). The position, age and development stage of the organisation in the market is reflected through the S-curve, and adoption and diffusion of innovation in a broader context are reflected through the Innovation adoption curve of Rogers (1995).

\section{Drivers of innovation}

Drivers include environmental factors such as deregulation, legislation, the blurring of industries, globalisation of markets, continuous change and the growing importance of sustainability; competition described as hyper-competition; and technology where technology changes business models (Janszen, 2000; Jones \& Kirby, 2002; Pyka \& Küppers, 2002).

\section{The classification of innovation}

This depends on the degree of change necessary in the organisation to adopt the innovation and is generally described as either radical or incremental (Darroch and McNaughton
(2002). Consequently, radical and incremental innovation are linked to types of innovation, such as technology, administrative and process innovation (Clark \& Staunton, 1990; Cooper, 1998; Mole \& Elliot, 1987).

\section{The Inhibitors of innovation}

The inhibitors identified through the literature review are rigid strategic planning, issues pertaining to culture, leadership and the execution thereof, structural modes, intolerance, strategic gridlock and tunnel vision (Andriopoulos, 2001; Arias, 1995; Borins, 2002; Buchen, 2003; Gurteen, 1998; Kilroy, 1999; Kono, 1988; Tucker, 2002; Quinn et al., 1997).

\section{The enablers of innovation}

The enablers form the core focus of innovation management. The clustering was done based on the interrelatedness of the elements to the category. The categories are Human Enablers consisting of emotional intelligence, creativity, core skills, creative and hybrid thinking skills, as well as systems thinking skills (Ahmed, 1998; Cooper, 1998; Gratton, 2000; Henry, 2001; Juniper, 1996; Klemm, 2004; McAdam \& McClelland, 2002; Quinn et al., 1997; Zhuang et al., 1999); Business Management Enablers consisting of leadership and management practices (Andriopoulos, 2001; Buchen, 2003; Clark \& Staunton, 1990; Cooper, 1998; Judge et al., 1997; Martins \& Terblanche, 2003; McAdam \& McClelland, 2002; Peters \& Waterman, 1982; Quinn et al., 1997; Senge, 1990; Tucker, 2002; Uecke, 2002; Urabe et al., 1988); Business Process Enablers consisting of recruitment, diversity, reward, performance management, knowledge management, change management, risk management, scanning ability, quality management, ideas management, communication management and relationship management (Buchen, 2003; Cooper, 1998; Darroch \& McNaughton, 2002; Henry, 2001; Justesen, 2001; Kaplan \& Norton, 2004; Senge, 1990; Tucker, 2002; Uecke, 2002); Structural Enablers consisting of multi-disciplinary teams, networks and collaboration; and

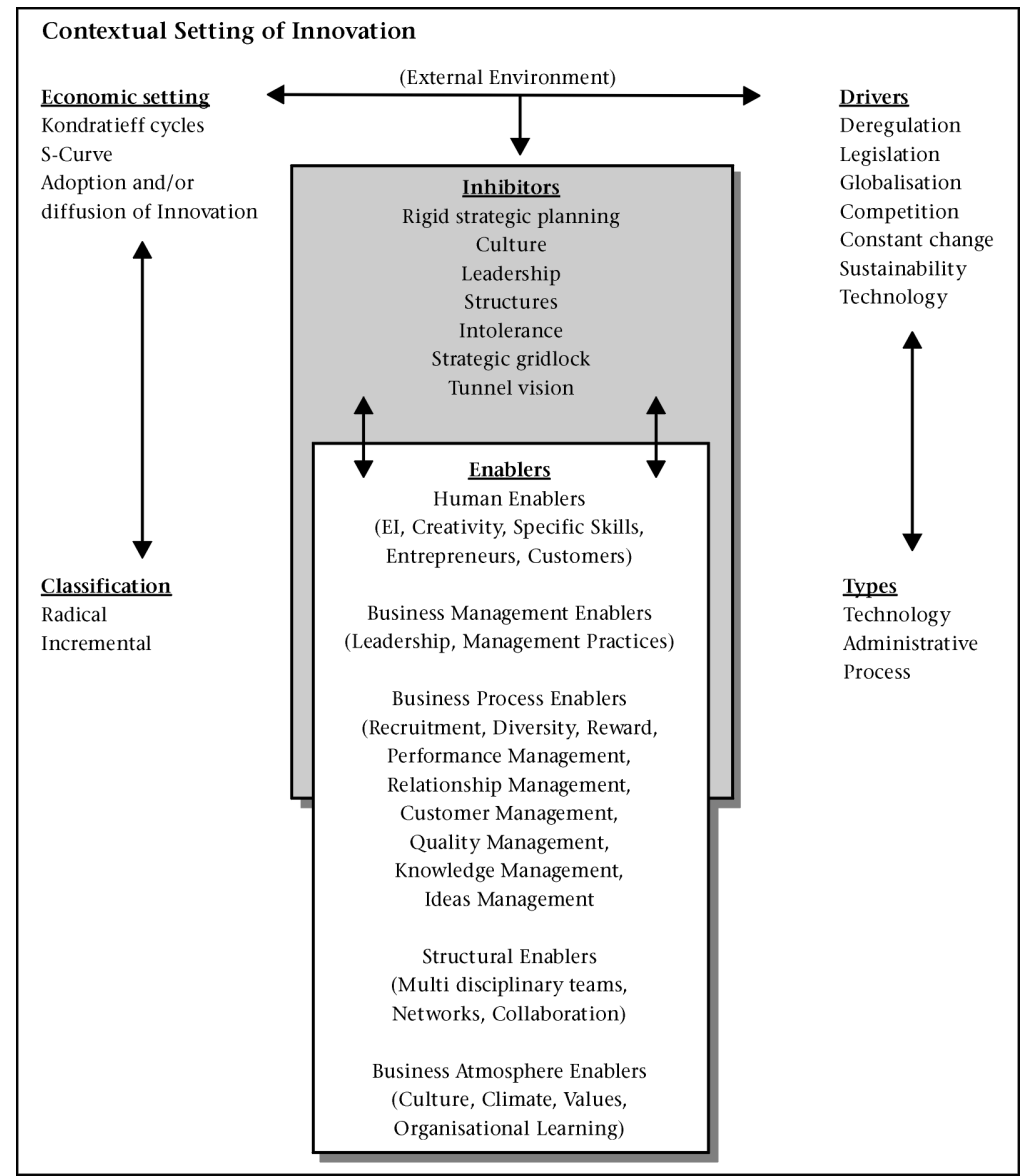

Figure 3: Proposed framework of innovation based on a literature review 
Business Atmosphere Enablers comprised of culture, climate, values and organisational learning (Ahmed, 1998; Andriopoulos, 2001; Arad et al., 1997; Brooking, 1997; Buckler, 1996; Cooper, 1998; Gratton, 2000; Johnson, 2001; Kono, 1988; Martins \& Terblanche, 2003; Tucker, 2002).

Following from the literature review a theoretical framework for depicting the building blocks of innovation is presented in Figure 3 and thereby achieving the primary and secondary objectives of this study.

\section{CONCLUSION}

It would seem that while many organisations subscribe to the importance of innovation, few have been able to maintain a culture that supports innovation as a top strategic priority. According to Drejer (2002) raising the inherent innovation effectiveness curve requires senior management to understand that innovation is not a discrete activity or event, but a multifunctional capability that requires several types of competencies that need a formal management framework. Enablers are appropriate in both rapidly changing and slowpaced contexts. Innovation, and its complexities, is the result of the combination and consolidation of many diverse elements in a non-linear fashion because new products integrate many elements into new functions, and innovation and its production requires the integration of many resources within one organisation. The success of the organisation with regard to its innovation rests on how well these building blocks of innovation in the theoretical framework of are managed.

\section{REFERENCE}

Abraham, J.L. \& Knight, J.D. (2001). Strategic Innovation: Leveraging creative action for more profitable growth. Strategy \& Leadership, 29 (1), 21-27.

Ahmed, P.K. (1998). Culture and Climate for Innovation. European Journal of Innovation Management, 1 (1), 30-43.

Amabile, A. (1988). A Model of creativity and innovation in organizations. Research in Organizational Behaviour, 10, 123-167.

Andriopoulos, C. (2001). Determinants of organisational creativity: a literature review. Management Decision, 39 (10), 834-841.

Andriopoulos, C. \& Lowe, A. (2000). Enhancing organisational creativity: the process of perpetual challenging. Management Decision, 38 (10), 734-42.

Arad, S., Hanson, M.A. \& Schneider, R.J. (1997). A framework for the study of relationships between organizational characteristics and organizational innovation. The Journal of Creative Behavior, 31 (1), 42-58.

Arias, J.T.G. (1995). Do networks really foster innovation? Management Decision, 33 (9),52-56.

Borins, S. (2002). Leadership and Innovation in the Public sector. Leadership and Organization Development Journal, 23 (8), 467-476.

Bostjan, A. \& Hisrich, R.D. (2003). Clarifying the intrapreneurship concept. Journal of Small and Enterprise Development, 10 (1), 7-24.

Brodtrick, O. (1999). Some thought on definitions of innovation. The Innovation Journal [The Public Sector Innovation Journal], 4 (3).

Brooking, A. (1997). Intellectual Capital. London: International Thomson Business Press.

Buckler, B. (1996). A learning process model to achieve continuous improvement and innovation. The Learning Organization, 3 (3), 31-39.

Buchen, I.H. (2003). Future-imbedded innovation methodologies. Foresight, 5 (3), 3-9.

Christensen, C.M. \& Raynor, M.E. (2003). The Innovator's Solution. Boston: Harvard Business School Press.
Clark, P. \& Staunton, N. (1990). Innovation in Technology and Organization. London: Routledge.

Cooper, J.R. (1998). A multidimensional approach to the adoption of innovation. Management Decision, 36 (8), 493-502.

Cottam, A. Ensor, J. \& Band, C. (2001). A Benchmark Study of Strategic Commitment to Innovation. European Journal of Innovation Management, 4 (2), 88-94.

Darroch, J. \& McNaughton, R. (2002). Examining the link between knowledge management practices and types of innovation. Journal of Intellectual Capital, 3 (3), 210-222.

Davenport, T.H. (1993). Process Innovation: reengineering work through information technology. Boston: Harvard Business School.

Drejer, A. (2002). Situations for innovation management: towards a contingency model. European Journal of Innovation Management, 5 (1), 4-17.

Drejer, A. \& Riis, J.O. (2001). New dimensions of competence development in industrial enterprises. The International Journal of Manufacturing Technology and Management, 2 (17), 660-682.

Drucker, P.F. (1955). The Practice of Management. Suffolk: Pan Books.

Drucker, P.F. (1985). Innovation and Entrepreneurship. New York: Harper \& Row.

Drucker, P.F. (1994). Innovation and Entrepreneurship: Practice and Principles. Great Britain: Butterworth Heineman.

Economist (1999). Long Wave Cycles of Innovation. Retrieved from the World Wide Web on 15/07/2004: http://www. people.hofstra.edu.

Ferrari, F.M. \& de Toledo, J.C. (2004). Analyzing the knowledge management through the product development process. Journal of Knowledge Management, 8 (1), 117-129.

Freeman, C. (1982). Innovation and Long-cycles of economic development. Paper presented at the International Seminar on Innovation and Development at the Industrial Sector. 25-27 August, University Campinas. Retrieved from the World Wide Web on 07/05/2003: http://www.catlibraries.org.

Goleman, D. (1995). Emotional Intelligence: Why it can matter more than IQ. London: Bloomsbury.

Gratton, L. (2000). Living Strategy: putting people at the heart of corporate purpose. Financial Times/Prentice Hall.

Grülke, W. (2001). Lessons in radical innovation. South Africans leading the world. Johannesburg: @One Communications.

Gurteen, D. (1998). Knowledge, creativity and Innovation. Journal of Knowledge Management, 2 (1), 5-13.

Handy, C. (1996). Beyond Certainty: the changing worlds of organisations. London: Arrow Business Books.

Henry, J. (2001). Creativity and Perception in Management. London: Sage Publications.

Hellström, T., Jacob, M. \& Malmquist, U. (2002). Guiding Innovation Socially and Cognitively: the innovation team model at Skandia Networks. European Journal of Innovation Management, 5 (3), 172-180.

Hivner, W, Hopkins, W.E. \& Hopkins, S.A. (2003). Facilitating, accelerating, and sustaining the innovation diffusion process: an epidemic modeling approach. European Journal of Innovation Management, 6 (2), 80-89.

Itami, H. (1988). Mobilizing invisible assets. Cambridge: Harvard University Press.

Janszen, F. (2000). The Age of Innovation: making business creativity a competence, not a coincidence. London: PrenticeHall.

Johnson, D. (2001). What is innovation and entrepreneurship? Lessons for larger organisations. Industrial and Commercial Training, 33 (4), 135-140.

Jones, T. \& Kirby, S. (2002). Taking Ideas to Market. UK: Capstone Publishing.

Judge, W.Q., Fryxell, G.E. \& Dooley, R.S. (1997). The new task of R\&D management: creating goal-directed communities for innovations. California Management Review, 39 (3), 72-85.

Juniper, D. (1996). Human Resource and creativity. Work Study, 45 (7), 15-22. 
Justesen, S.L. (2001). Innoversity: Master Thesis in Intercultural Management. MPP Working Paper No. 6/2001.

Kaplan, R.S. \& Norton, D.P. (2004). Strategy Maps. Converting intangible assets into tangible outcomes. Boston: Harvard Business School Press.

Kilroy, D.B. (1999). Creating the Future: how creativity and innovation drive shareholder wealth. Management Decision, 37 (4), 363-374.

Klemm, W.R. (2004). Leadership: Creativity and Innovation. Conference paper: Concepts for Airforce Leadership (AU-24). Retrieved from the World Wide Web on 07/05/2003: http://www.au.af.mil.

Kim, J. \& Wilemon, D. (2002). Strategic issues in managing innovation's fuzzy front-end. European Journal of Innovation Management, 5 (1), 27-39.

Kono,T. (1988). Factors affecting the creativity of organizations:an approach from new product development. In Urabe, K.; Child, J.; Kagono, T. Walter de Gruyter (eds.) Innovation and management: International comparisons. Berlin. 105-144.

Kuczmarski, T.D. (1996). Fostering an innovation mindset. Journal of Consumer Marketing, 13 (6), 7-13.

Martins, E.C. \& Terblanche, F. (2003). Building organisational culture that stimulates creativity and innovation. European Journal of Innovation Management, 6 (1), 64-74.

McAdam, R \& McClelland, J. (2002). Individual and team-based idea generation within innovation management: organisational and research agendas. European Journal of Innovation Management, 5 (2), 86-97.

McGivern, M.H. \& Tvorik, S.J. (1997). Determinants of organizational performance. Management Decision, 35 (6), 417-435.

Mohamed, M.A.K. (2002). Assessing determinants of departmental innovation: an exploratory multi-level approach. Personnel Review, 31 (5), 620-641.

Mole, V. \& Elliot, D. (1987). Enterprising Innovation: An alternative approach. London: Frances Pinter.

Mumford, M.D., Whetzel, D.L. \& Reiter-Palman, R. (1997). Thinking creatively at work: organization influences on creative problem-solving. The Journal of Creative Behavior, 31 (1), 7-17.

Pech, R.J. (2001). Reflections. Termites, group behaviour, and the loss of innovation: conformity rules! Journal of Managerial Psychology, 16 (7), 559-574.

Peters, T. \& Waterman, R. (1982). In Search of Excellence: Lessons from America's Best Run Companies. New York: Harper and Row.
Pyka, A. \& Küppers, G. (2002). Innovation Networks: Theory and Practice. Cheltenham, UK: Edward Elgar.

Quinn, J.B., Baruch, J.J. \& Zien, K.A. (1997). Innovation Explosion: using intellect and software to revolutionize growth strategies. New York: The Free Press.

Rogers, E.M. (1995). Diffusion of Innovations. New York: The Free Press.

Schurink, W.J. \& Schurink, E.M. (2001). Lecture One. Deciding to use a qualitative research approach. In: Schurink, W.J. Models of qualitative research. Department of Human Resource Management. Johannesburg: RAU.

Senge, P.M. (1990). The Fifth Discipline. The art and practice of the learning organization. New York: Doubleday Currency.

Silverman, L.L. (1999). Critical Shift. The future of quality in organizational performance. Wisconsin: ASQ Quality Press.

Slywotsky, A. \& Wise, R. (2003). Three keys to groundbreaking growth: A demand innovation strategy, nurturing practices, and chief growth officer. Strategy \& Leadership, 31 (5), 12-19.

Sy, T. \& Côté, S. (2004). Emotional Intelligence: A key ability to succeed in the matrix organization. Journal of Management Development, 23 (5), 437-455.

Sundbo, J. (1998). The Theory of Innovation: Entrepreneurs, Technology and Strategy. Northampton: Edward Elgar.

Thomson, K. (1998). Emotional Capital: Capturing hearts and minds to create lasting Business Success. UK: Capstone.

Tucker, R.B. (2002) Driving Growth through Innovation. How leading firms are transforming their futures. San Francisco: Berrett-Koehler Publishers.

Tucker, R.B. (2003). Innovation and growth. Strategy \& Leadership, 19 (4), 29-31.

Uecke, O. (2002). AIO: An Innovative Organization. Paper within entrepreneurial creativity. Jönköping International Business School. Jönköping University. 1-13.

Urabe, K. (1988). Innovation and the Japanese management system. Innovation and management.international comparisons. In Urabe, K.; Child, J.; Kagono, T.; Walter de Gruyter (eds.) Innovation and management: International comparisons. Berlin. 3-25.

Veldsman, T.H. (2002). Into the People Effectiveness Arena Johannesburg: Knowledge Resources.

Wu, W., Chiang, C. \& Jiang, J. (2002). Interrelationships between TMT management styles and organizational innovation. Industrial Management \& Data Systems, 102 (3), 171-183.

Zhuang, L., Williamson, D. \& Carter, M. (1999). Innovate or liquidate - are all organisations convinced? A two-phased study into the innovation process. Management Decision, 37 (1), 57-71. 